\title{
Cytokeratin 17 and Ki-67: Immunohistochemical markers for the differential diagnosis of keratoacanthoma and squamous cell carcinoma
}

\author{
CEM LEBLEBICI $^{1}$, ESRA PASAOGLU $^{1}$, CANAN KELTEN $^{1}$, SEHER DARAKCI $^{2}$ and NEVRA DURSUN ${ }^{1}$ \\ ${ }^{1}$ Department of Pathology, Istanbul Education and Research Hospital, Istanbul 34098; \\ ${ }^{2}$ Department of Pathology, Erciyes University, School of Medicine, Kayseri 38039, Turkey
}

Received May 20, 2016; Accepted November 4, 2016

DOI: $10.3892 / 01.2017 .5793$

\begin{abstract}
The clinical and histopathological distinction between keratoacanthoma (KA) and squamous cell carcinoma (SCC) is essential, but frequently difficult to make. The utility of CK17 and Ki-67 expression in distinguishing between KA and SCC was investigated. Immunohistochemical staining patterns for $\mathrm{CK} 17$ and $\mathrm{Ki}-67$ were evaluated in $24 \mathrm{KA}$ and 27 SCC cases. The pattern of staining was evaluated as central, peripheral or diffuse, according to the basal/peripheral and suprabasal/central cell staining of tumor lobules. The sensitivity and specificity of the central CK17 staining pattern in the identification of KA were 92 and $70 \%$, respectively. Additionally, the sensitivity and specificity of the diffuse Ki-67 staining pattern in the identification of SCC were 81 and $100 \%$, respectively. The results of the present study suggest that a diffuse Ki-67 staining pattern may be used to diagnose SCC, while a central CK17 staining pattern indicates KA. However, the KA-like SCC cases exhibited mixed patterns, which limits the effectiveness of these markers.
\end{abstract}

\section{Introduction}

Cutaneous squamoproliferative lesions with crateriform architecture are frequently encountered $(1,2)$. KAs are keratin-plugged, crater-shaped nodules that develop predominantly on the surfaces of the body exposed to the sun and typically grow rapidly, prior to regression (2). Although the majority of KAs are solitary and sporadic, multiple lesions may develop in association with certain syndromes (3). The etiology of KAs remains unclear; however, it is currently considered that they develop from the pilosebaceous unit $(3,4)$.

Correspondence to: Dr Cem Leblebici, Department of Pathology, Istanbul Education and Research Hospital, 24 Abdurrahman Nafiz Gürman Street, Istanbul 34098, Turkey

E-mail: cleblebici@gmail.com

Key words: cytokeratin 17, proliferation marker protein Ki-67, keratoacanthoma, skin, squamous cell carcinoma
Histopathological differentiation between keratoacanthoma (KA) and squamous cell carcinoma (SCC) is difficult. It is occasionally impossible to distinguish between these lesions through clinical and histopathological analysis, particularly in small biopsy specimens (1). Therefore, multiple immunohistochemical markers have been investigated to overcome this limitation (5). Proliferation marker protein Ki-67 (Ki-67) is a cell cycle-regulating protein frequently studied in squamoproliferative lesions and the most useful marker among immunohistochemical markers $(6,7)$. Cytokeratin (CK) 17 is a basal/myoepithelial cell-associated keratin protein that is expressed in the outer root sheath of wild-type hair follicles (8). It is not expressed in the normal epidermis but induced in activated keratinocytes (9), and its expression is associated with disease progression in SCCs of the anus, oral cavity and uterine cervix (10-12). To the best of our knowledge, CK17 expression has not been investigated in KA. The aim of the present study was to investigate the utility of CK17 and Ki-67 as adjunctive markers for the differential diagnosis of KA and SCC.

\section{Materials and methods}

Case selection. Tissue samples of patients diagnosed with KA or SCC of the skin between 1st January 2011 and 1st January 2015, were obtained from the Pathology Laboratory of the Istanbul Research and Educational Hospital (Istanbul, Turkey). Patient number, age and gender are presented in Tables I and II. Hematoxylin and eosin-stained slides of 43 cases of SCC and 24 cases of KA were re-examined. All lesions had been completely removed by surgery. Cases of moderately and poorly differentiated SCC were excluded. Due to the considerable overlap with KA, only grade 1 cases of SCC exhibiting a predominantly endophytic growth pattern were included in the present study. KA-like and crateriform cases of SCC were determined using the original characterization criteria of Misago et al (2). KA-like SCC lesions exhibit the characteristic histopathological architectural pattern of $\mathrm{KA}$, and the characteristic neoplastic lobules of KA in certain regions. This includes the regular distribution of two types of cells: Large, pale pink cells with a glassy appearance thinly surrounded by a few layers of basophilic cells, which 
are also asymmetrical and/or deeply invasive lesions, and the majority exhibit nuclear atypia and frequent mitotic figures. Crateriform SCC lesions arise from actinic keratosis, have crateriform architecture and lack KA-resembling cytological features (2).

Immunohistochemistry. Immunohistochemical reactions were performed on paraffin tissue sections using an automated immunohistochemical stainer (Ventana BenchMark ULTRA, Ventana Medical Systems, Inc., Tucson, AZ, USA), according to the manufacturer's protocol. Detection was performed using the Ventana ultraVIEW DAB Detection kit (Ventana Medical Systems, Inc.). The 4- $\mu \mathrm{m}$-tissue sections were deparaffinized using the EZ Prep solution (Ventana Medical Systems, Inc.; cat. no. 05279771001). Heat-induced antigen retrieval was performed using the Cell Conditioning 1 solution (Ventana Medical Systems, Inc.; cat. no. 05424569001) at $98^{\circ} \mathrm{C}$ for $60 \mathrm{~min}$. Endogenous peroxidase activity was blocked by treatment with the ultraVIEW inhibitor (Ventana Medical Systems, Inc.; cat no. 05269806001$)$ in $3 \% \mathrm{H}_{2} \mathrm{O}_{2}$ for $4 \mathrm{~min}$ at $37^{\circ} \mathrm{C}$. Slides were incubated with the following primary antibodies for $60 \mathrm{~min}$ at $37^{\circ} \mathrm{C}$ : Ready-to-use CONFIRM anti-Ki-67 rabbit monoclonal antibody (cat. no. 30-9; Ventana Medical Systems); and ready-to-use anti-CK17 rabbit monoclonal antibody (cat. no. SP95; Ventana Medical Systems, Inc.). The ultraView Universal DAB Detection kit incorporates multimer technology, whereby the ultraVIEW streptavidin-horseradish peroxidase (HRP) enzyme is directly conjugated to the secondary antibody. Slides were incubated with a secondary antibody of ultraVIEW HRP Multimer (Ventana Medical Systems, Inc.; cat. no. 05269806001$)$ at $37^{\circ} \mathrm{C}$ for $8 \mathrm{~min}$ and a diaminobenzidine $+\mathrm{H}_{2} \mathrm{O}_{2}$ substrate for $8 \mathrm{~min}$, which was followed by counterstaining with hematoxylin and bluing reagent at $37^{\circ} \mathrm{C}$, for 16 and $4 \mathrm{~min}$, respectively. Slides were washed with Tris buffer ( $\mathrm{pH}$ 7.6) and mounted using a xylene-based mounting media.

The pattern of immunohistochemical expression of CK17 was determined for all lesions. As reported in previous studies $(8,10,13-15)$, the interpretation of the CK17 staining pattern was modeled on the physiological immunolocalization of keratin expression in the basal and suprabasal layers of human epithelia, specifically in the hair follicle. The staining patterns were evaluated as central and diffuse, according to the basal/peripheral and suprabasal/central cell staining of the tumor lobules. The following conditions were considered to indicate a central pattern (CP) of staining: i) CK17 expression was limited to the center (suprabasal or inner two-thirds of the tumor cell lobules) without peripheral staining; ii) the peripheral/basal cells of the tumor lobules stained weaker than the central/suprabasal cells; iii) mixed staining patterns were observed as described in i) and ii); and iv) strong expression was present in $<10 \%$ of peripheral/basal cells, while the rest of the lesion exhibited the staining pattern described in i) and/or ii). A diffuse pattern (DP) of staining was diagnosed if the strong staining of peripheral/basal cells and that of central/suprabasal cells comprised $>10 \%$ of the whole lesion.

A peripheral pattern (PP) of staining was diagnosed if the basal or peripheral cells of the tumor lobules were stained. Suprabasal or central staining of the lobules with basal/peripheral staining was interpreted as a DP.
Statistical analysis. Statistical analysis was performed using SPSS statistical software (version 13.0; SPSS, Inc., Chicago, IL, USA). The sensitivity, specificity and positive/negative predictive values of the $\mathrm{CK} 17 \mathrm{CP}$ staining for the detection of KA and of the Ki-67 DP staining for the detection of SCC were calculated as follows: Sensitivity $=[$ true positive/(true positive + false negative)]; specificity $=[$ true negative/(false positive + true negative)]; positive predictive value $=[$ true positive/(true positive + false positive)]; and negative predictive value $=[$ true negative/(true negative + false negative $)]$. CK17 and $\mathrm{Ki}-67$ expression patterns were compared between KA and SCC cases using the two-tailed Fisher's exact test. The Kruskal-Wallis and Mann-Whitney $U$ tests were used to examine other quantitative data. $\mathrm{P}<0.05$ was considered to indicate a statistically significant difference.

\section{Results}

A total of $24 \mathrm{KA}$ and 27 SCC samples were obtained. Prominent crateriform architecture was present in 10/27 SCC samples, Of these, 6 were defined as KA-like SCC and 4 as crateriform SCC. The clinicopathological and immunohistochemical features of each sample are summarized in Tables I and II.

The KA samples were obtained from 10 male and 14 female patients with a mean age of 63.7 years (range, $42-86$ years). The tumors were located predominantly in the head and neck region $(67 \%)$. The median tumor size was $0.9 \mathrm{~cm}$ (range, 0.4-3.5 cm), and the median duration of the lesions was 2.5 months. Duration of the lesions was obtained from the patient history files. The SCC samples were obtained from 22 male and 5 female patients with a mean age of 74.6 years (range, 56-90 years). The tumors were located predominantly in the head and neck region (85\%). The median tumor size was $1.7 \mathrm{~cm}$ (range, 0.4-3.5 cm), and the median duration of the lesions was 5 months. The mean age of the patients with SCC was significantly higher compared with that of patients with KA $(\mathrm{P}=0.0358)$. The number of male patients with SCC was significantly higher compared with that of female patients $(\mathrm{P}=0.0261)$. The duration of the KA lesions (mean, 3.8 months) was lower compared with that of the SCC lesions (mean, 13.3 months)

A total of 51/51 (100\%) cases stained positive for CK17 following immunohistochemical analysis. A total of 22/24 (92\%) KA cases exhibited a CK17 CP (Figs. 1-3), while $2 / 24$ cases $(8 \%)$ exhibited a CK17 DP. A total of 8/27 (30\%) SCC cases exhibited a CK17 CP, while 19/27 cases (70\%) exhibited a CK17 DP (Table III). The incidence of a CK17 CP was increased in the KA cases compared with that in the SCC cases. The sensitivity and specificity of a CK17 CP in the identification of KA was 92 and $70 \%$, respectively (Table IV). All KA cases (24/24) exhibited a Ki-67 PP. A total of 22/27 (81\%) SCC cases exhibited a Ki-67 DP (Fig. 4) and the remaining 5 SCC cases exhibited a Ki-67 PP (Table V). The incidence of a Ki-67 DP was increased in the SCC cases compared with that in the KA cases. The sensitivity and specificity of a Ki-67 DP in the identification of SCC was 81 and $100 \%$, respectively (Table VI).

The majority of KA cases exhibited a Ki-67 PP and CK17 CP; therefore this staining pattern was named the 
Table I. Clinicopathological and immunohistochemical features of keratoacanthoma samples.

Feature

\begin{tabular}{|c|c|c|c|c|c|c|c|}
\hline Patient no. & Age (years) & Gender & Location & $\begin{array}{l}\text { Duration of the } \\
\text { lesions (months) }\end{array}$ & Size $(\mathrm{cm})$ & $\begin{array}{l}\text { CK17 staining } \\
\text { pattern }\end{array}$ & $\begin{array}{l}\text { Ki-67 staining } \\
\text { pattern }\end{array}$ \\
\hline 1 & 58 & M & Face & 2.0 & 0.5 & $\mathrm{C}$ & $\mathrm{P}$ \\
\hline 2 & 76 & M & Upper extremity & 3.0 & 0.7 & $\mathrm{C}^{\mathrm{a}}$ & $\mathrm{P}$ \\
\hline 3 & 42 & M & Neck & 3.0 & 1.0 & $\mathrm{C}$ & $\mathrm{P}$ \\
\hline 4 & 71 & $\mathrm{~F}$ & Face & 4.5 & 1.0 & $\mathrm{C}^{\mathrm{a}}$ & $\mathrm{P}$ \\
\hline 5 & 69 & $\mathrm{~F}$ & Face & 1.0 & 0.8 & $\mathrm{C}^{\mathrm{a}}$ & $P$ \\
\hline 6 & 60 & $\mathrm{~F}$ & Face & 1.0 & 2.0 & $\mathrm{C}^{\mathrm{a}}$ & $\mathrm{P}$ \\
\hline 7 & 53 & $\mathrm{~F}$ & Upper extremity & 2.0 & Unknown & $\mathrm{C}^{\mathrm{a}}$ & $\mathrm{P}$ \\
\hline 8 & 59 & M & Head & Unknown & 0.8 & $\mathrm{C}^{\mathrm{a}}$ & $\mathrm{P}$ \\
\hline 9 & 79 & M & Face & 1.5 & 1.7 & $\mathrm{C}^{\mathrm{a}}$ & $\mathrm{P}$ \\
\hline 10 & 47 & M & Lower extremity & Unknown & 1.1 & $\mathrm{C}^{\mathrm{a}}$ & $\mathrm{P}$ \\
\hline 11 & 84 & M & Face & Unknown & Unknown & $\mathrm{D}$ & $\mathrm{P}$ \\
\hline 12 & 54 & $\mathrm{~F}$ & Face & Unknown & 0.6 & $\mathrm{C}^{\mathrm{a}}$ & $\mathrm{P}$ \\
\hline 13 & 48 & F & Neck & Unknown & Unknown & $\mathrm{C}$ & $\mathrm{P}$ \\
\hline 14 & 57 & $\mathrm{~F}$ & Trunk & 12 & 0.6 & D & $\mathrm{P}$ \\
\hline 15 & 60 & F & Neck & 6.0 & 0.4 & $\mathrm{C}$ & $\mathrm{P}$ \\
\hline 16 & 82 & M & Upper extremity & 3.0 & 0.9 & $\mathrm{C}$ & $\mathrm{P}$ \\
\hline 17 & 82 & $\mathrm{~F}$ & Face & 2.0 & 3.5 & $\mathrm{C}^{\mathrm{a}}$ & $\mathrm{P}$ \\
\hline 18 & 45 & $\mathrm{~F}$ & Trunk & 1.0 & 1.0 & $\mathrm{C}$ & $\mathrm{P}$ \\
\hline 19 & 72 & M & Face & 2.0 & 1.2 & $\mathrm{C}$ & $\mathrm{P}$ \\
\hline 20 & 67 & $\mathrm{~F}$ & Head & 5.0 & 0.8 & $\mathrm{C}^{\mathrm{a}}$ & $\mathrm{P}$ \\
\hline 21 & 56 & $\mathrm{~F}$ & Trunk & 11.0 & 0.6 & $\mathrm{C}$ & $\mathrm{P}$ \\
\hline 22 & 66 & M & Upper extremity & 1.0 & 1.0 & $\mathrm{C}^{\mathrm{a}}$ & $\mathrm{P}$ \\
\hline 23 & 56 & $\mathrm{~F}$ & Neck & 6.0 & 0.4 & $\mathrm{C}$ & $\mathrm{P}$ \\
\hline 24 & 86 & $\mathrm{~F}$ & Face & Unknown & 1.7 & $\mathrm{C}$ & $\mathrm{P}$ \\
\hline
\end{tabular}

${ }^{a}$ These cases exhibited weak peripheral/basal cell staining. CK17, cytokeratin 17; Ki-67, proliferation marker protein Ki-67; M, male; $\mathrm{F}$, female; $\mathrm{C}$, central staining pattern; $\mathrm{D}$, diffuse staining pattern; $\mathrm{P}$, peripheral staining pattern.

KA-like staining pattern (Figs. 1-3). The KA-like staining pattern was exhibited by $22 / 24 \mathrm{KA}$ cases $(92 \%)$ and by 2/27 SCC cases (7\%). The SCC cases primarily exhibited a Ki-67 and CK17 DP; this was therefore named the SCC-like staining pattern (Figs. 4-6). The SCC-like staining pattern was exhibited by $16 / 27$ SCC cases (59\%) and by $0 / 22 \mathrm{KA}$ cases $(0 \%)$. All KA-like SCC cases were located on the face or head and exhibited rapid growth, similar to the KA cases. Crateriform SCC lesions were clinically characterized as long-standing nodules, and all exhibited a Ki-67 and CK17 DP. Also, CK17 was expressed in the suprabasal cells of the outer root sheath of the normal hair follicles in the examined cases (Fig. 7).

\section{Discussion}

There is currently no consensus within the fields of dermatology and dermatopathology as to whether KA is a benign tumor, a pseudomalignancy, a regressing malignancy or an SCC variant. The lesion was previously considered to be a benign neoplasm and has been described using various names, including molluscum sebaceum and self-limiting epithelioma (16). Certain KA lesions were demonstrated to not exhibit metastasis or recurrence despite the presence of perineural infiltration (17). By contrast, there have been cases of metastases purported to originate from KAs, which fulfill the diagnostic histological criteria of KA $(3,18)$. KA may be defined as a distinct subtype of SCC that exhibits low-grade malignancy and typically regresses; however, it is able to progress into invasive SCC (2). KA-like SCC may be used to describe lesions that histopathologically resemble KA but exhibit eccentric architecture and prominent atypical cytological features $(2,19)$.

Misago et al (2) attempted to standardize the terminology used to define KAs and associated neoplasms exhibiting a crateriform architecture. The following six histopathological classifications were identified: i) KA; ii) KA-like SCC; iii) KA with malignant transformation; iv) infundibular SCC (crateriform); v) crateriform SCC arising from actinic keratosis; and vi) crateriform Bowen's disease. In the present study, 6 lesions were described as KA-like SCC and 4 as crateriform SCC according to the above classification. No cases of KA with 
Table II. Clinicopathological and immunohistochemical features of squamous cell carcinoma samples.

\begin{tabular}{|c|c|c|c|c|c|c|c|c|}
\hline \multirow[b]{2}{*}{ Patient no. } & \multicolumn{8}{|c|}{ Feature } \\
\hline & $\begin{array}{l}\text { Age } \\
\text { (years) }\end{array}$ & Gender & $\begin{array}{l}\text { Histological } \\
\text { subtype }\end{array}$ & Location & $\begin{array}{l}\text { Duration of the } \\
\text { lesions (months) }\end{array}$ & $\begin{array}{l}\text { Size } \\
(\mathrm{cm})\end{array}$ & $\begin{array}{l}\text { CK17 staining } \\
\text { pattern }\end{array}$ & $\begin{array}{c}\text { Ki-67 staining } \\
\text { pattern }\end{array}$ \\
\hline 1 & 56 & M & NOS & Face & 24.0 & 1.4 & $\mathrm{C}$ & $\mathrm{P}$ \\
\hline 2 & 83 & M & NOS & Neck & 16.0 & 1.5 & C & D \\
\hline 3 & 88 & $\mathrm{~F}$ & NOS & Face & 11.0 & 1.3 & $\mathrm{D}$ & $\mathrm{D}$ \\
\hline 4 & 62 & M & NOS & Head & Unknown & 2.0 & $\mathrm{D}$ & $\mathrm{D}$ \\
\hline 5 & 78 & $\mathrm{~F}$ & NOS & Face & Unknown & 2.5 & $\mathrm{D}$ & $\mathrm{D}$ \\
\hline 6 & 68 & M & NOS & Neck & 16.0 & 2.5 & $\mathrm{D}$ & $\mathrm{D}$ \\
\hline 7 & 88 & M & NOS & Head & 12.0 & 3.5 & D & $\mathrm{D}$ \\
\hline 8 & 81 & M & NOS & Head & 14.0 & 1.4 & $\mathrm{D}$ & $\mathrm{D}$ \\
\hline 9 & 89 & $\mathrm{~F}$ & NOS & Face & 22.0 & 2.5 & $\mathrm{D}$ & $\mathrm{P}$ \\
\hline 10 & 64 & M & NOS & Face & Unknown & 1.5 & $\mathrm{D}$ & $\mathrm{D}$ \\
\hline 11 & 81 & M & NOS & Lower extremity & Unknown & 3.5 & $\mathrm{D}$ & $\mathrm{D}$ \\
\hline 12 & 90 & M & NOS & Head & Unknown & 1.9 & $\mathrm{D}$ & $\mathrm{D}$ \\
\hline 13 & 66 & M & NOS & Face & 11.0 & 1.0 & $\mathrm{C}$ & $\mathrm{D}$ \\
\hline 14 & 86 & M & NOS & Upper extremity & 14.0 & 2.3 & $\mathrm{D}$ & $\mathrm{P}$ \\
\hline 15 & 76 & M & NOS & Upper extremity & Unknown & 1.2 & $\mathrm{D}$ & $\mathrm{D}$ \\
\hline 16 & 71 & M & NOS & Head & Unknown & 0.5 & $\mathrm{C}$ & $\mathrm{D}$ \\
\hline 17 & 73 & M & NOS & Head & Unknown & 1.0 & $\mathrm{C}$ & $\mathrm{D}$ \\
\hline 18 & 67 & M & KA-like & Face & 3.0 & 1.4 & $\mathrm{C}$ & $\mathrm{P}$ \\
\hline 19 & 77 & M & KA-like & Head & Unknown & 2.3 & $\mathrm{D}$ & $\mathrm{P}$ \\
\hline 20 & 81 & $\mathrm{~F}$ & KA-like & Face & 6.0 & 1.6 & $\mathrm{C}$ & $\mathrm{D}$ \\
\hline 21 & 69 & M & KA-like & Head & 3.0 & 1.5 & $\mathrm{D}$ & $\mathrm{D}$ \\
\hline 22 & 59 & M & KA-like & Head & 2.5 & 3.5 & $\mathrm{C}$ & $\mathrm{D}$ \\
\hline 23 & 67 & $\mathrm{~F}$ & KA-like & Face & 5.0 & 1.7 & $\mathrm{D}$ & $\mathrm{D}$ \\
\hline 24 & 59 & M & Crateriform & Face & 15.0 & 2.0 & $\mathrm{D}$ & $\mathrm{D}$ \\
\hline 25 & 82 & M & Crateriform & Face & 19.0 & 3.0 & $\mathrm{D}$ & $\mathrm{D}$ \\
\hline 26 & 67 & M & Crateriform & Upper extremity & Unknown & 1.0 & $\mathrm{D}$ & $\mathrm{D}$ \\
\hline 27 & 86 & M & Crateriform & Head & 32.0 & 1.8 & $\mathrm{D}$ & $\mathrm{D}$ \\
\hline
\end{tabular}

CK17, cytokeratin 17; Ki-67, proliferation marker protein Ki-67; M, male; F, female; C, central staining pattern; D, diffuse staining pattern; $\mathrm{P}$, peripheral staining pattern; NOS, not otherwise specified; KA, keratoacanthoma.

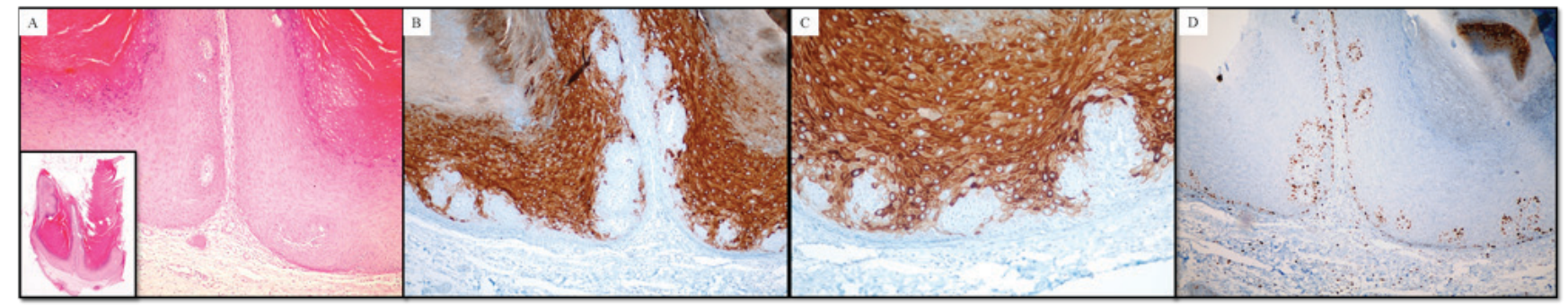

Figure 1. Representative images of (A) hematoxylin and eosin-stained KA (magnification, x100) exhibiting a central CK17 IHC staining pattern at (B) magnification, x100 and (C) magnification, x200, or (D) a peripheral proliferation marker protein Ki-67 IHC staining pattern (magnification, x100). These staining patterns constitute the KA-like staining pattern, exhibiting no basal or peripheral CK17 staining. KA, keratoacanthoma; CK17, cytokeratin 17; IHC, immunohistochemistry.

malignant transformation or infundibular SCC were identified in the present study.

Multiple immunohistochemical markers have been investigated in order to differentiate between KA and SCC.
Immunoperoxidase staining has been used to demonstrate that transforming growth factor (TGF)- $\alpha$ primarily exhibits a DP in the one or two layers of KA samples, while exhibiting no PP (20). Similarly, TGF- $\alpha$ has been demonstrated to 


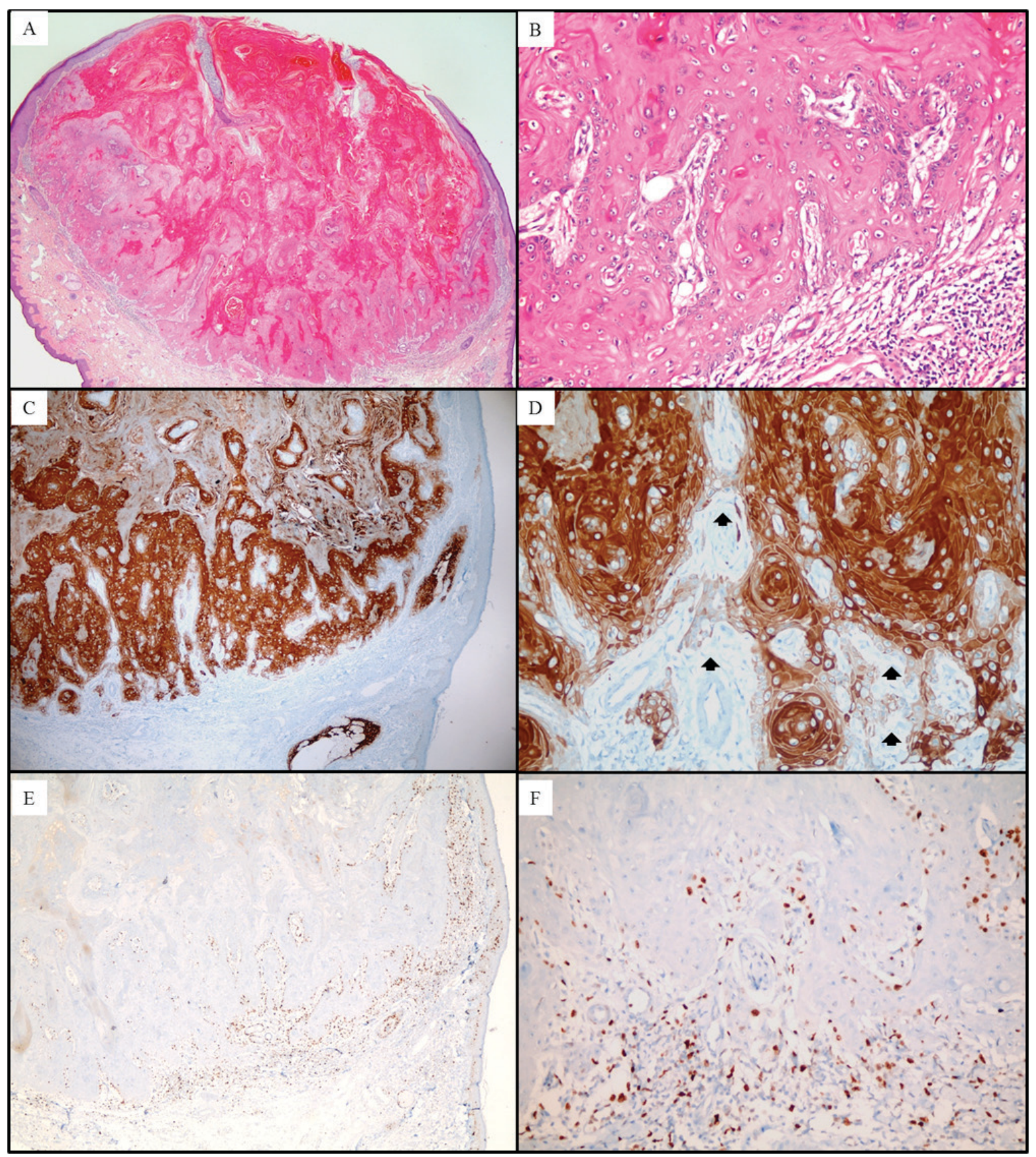

Figure 2. Representative images of hematoxylin and eosin-stained KA, at (A) magnification x20 and (B) magnification x200, exhibiting a central CK17 IHC staining pattern, at (C) magnification $\times 40$ and (D) magnification x200, or a peripheral proliferation marker protein Ki-67 IHC staining pattern, at (E) magnification $\mathrm{x} 40$ and (F) magnification x200. These staining patterns constitute the KA-like staining pattern, exhibiting weak basal or peripheral CK17 staining. Black arrowheads indicate weak peripheral CK17 staining. KA, keratoacanthoma; CK17, cytokeratin 17; IHC, immunohistochemistry.

exhibit a weak PP in one or two layers of SCC samples (20). Lu et al (5) demonstrated decreased p21 and proliferating cell nuclear antigen expression in KA samples despite increased p53 expression. Vasiljević et al (21) suggested that decreased expression of the anti-apoptotic protein Bcl-2-like protein 1 in KA compared with SCC is a differential marker. By contrast, evaluation of syndecan-1, E-cadherin and catenin staining revealed subtle differences in staining patterns between KA and $\operatorname{SCC}(22,23)$.

Multiple studies have identified significant overexpression of Ki-67 in SCC compared with that in KA $(6,7,21,23-26)$. Scola et al (6) suggested that a Ki-67 fraction of $<20 \%$ may therefore be indicative of KA. All SCC cases in the study by
Shimizu et al (24) also exhibited a positive Ki-67 fraction of $>20 \%$. In these studies, $\mathrm{Ki}-67$ expression was primarily restricted to basal cells in KAs, whereas it was distributed diffusely throughout SCC samples $(6,24)$. In addition, a study investigating subungual cases of KA and SCC evaluated Ki-67 immunohistochemical staining in a semiquantitative manner, according to the percentage of stained basal cells and the presence or absence of suprabasal cell staining (7). It was observed that subungual KA exhibited an occasional Ki-67 basal staining pattern, while subungual SCC cases exhibited a Ki-67 DP (7). A Ki-67 PP was therefore defined as the staining of basal cells only, and a Ki-67 DP was defined as the staining of basal and suprabasal/central cells, to ensure practical and 


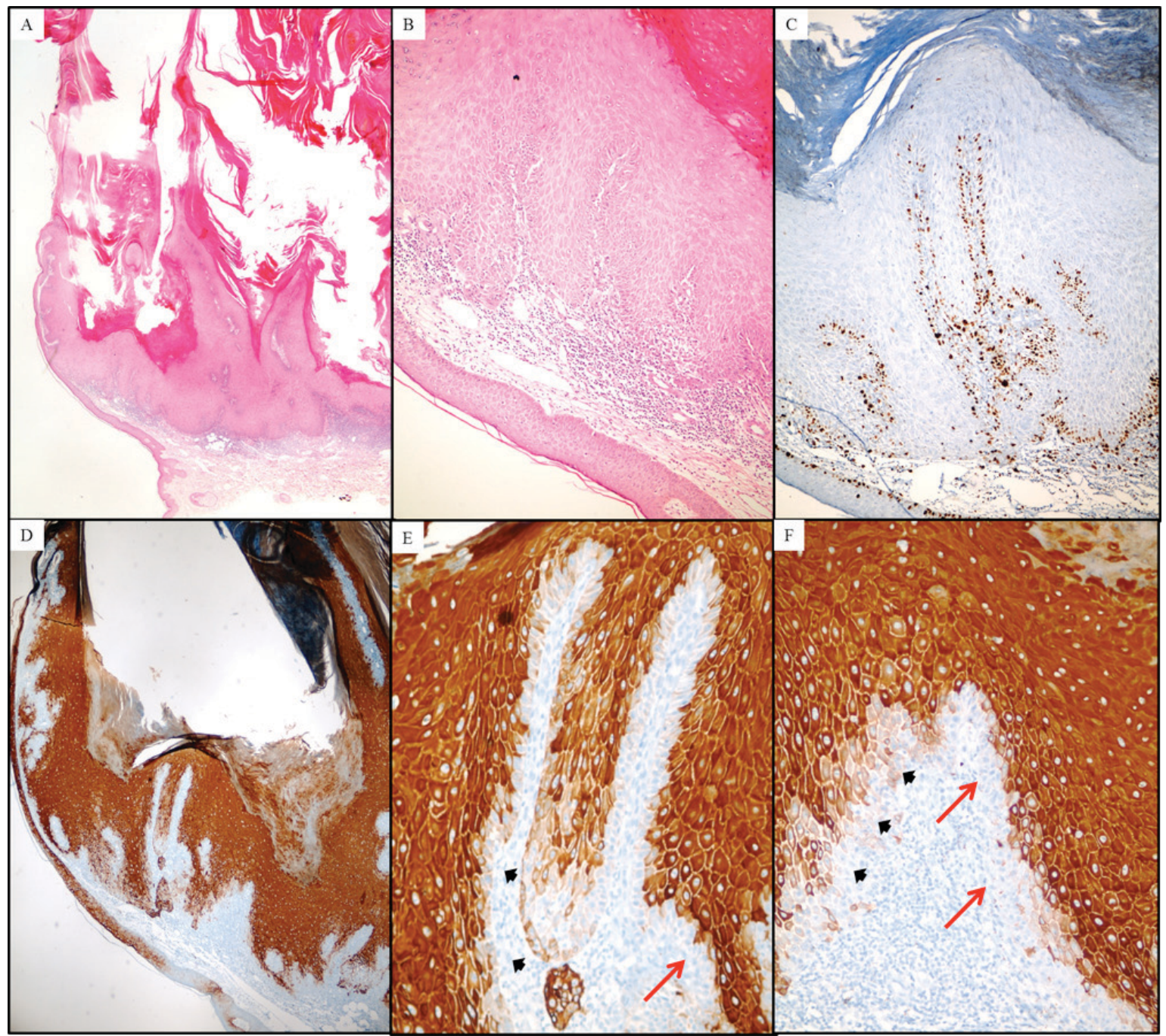

Figure 3. Representative images of hematoxylin and eosin-stained keratoacanthoma, at (A) magnification, $\mathrm{x} 40$ and (B) magnification, x100, exhibiting (C) a peripheral proliferation marker protein Ki-67 IHC staining pattern (magnification, x100) or a central CK17 IHC staining pattern at (D) magnification, x40, and magnification, x200 in (E) one field and vision and (F) another field of vision. Red arrowhead, no CK17 staining of basal cells; black arrowhead, weak CK17 staining of basal cells. CK17, cytokeratin 17; IHC, immunohistochemistry.

Table III. Cytokeratin 17 staining patterns in the SCC and KA cases.

\begin{tabular}{lrr}
\hline & \multicolumn{3}{c}{$\begin{array}{c}\text { Tumor type } \\
\text { (no. of cases) }\end{array}$} \\
\cline { 2 - 3 } Staining pattern & SCC & KA \\
\hline Central & 8 & 22 \\
Diffuse & 19 & 2 \\
\hline
\end{tabular}

SCC, squamous cell carcinoma; KA, keratoacanthoma.

rapid assessment (7). The Ki-67 expression percentage was not calculated (7).

CK17 was initially described within the pilosebaceous unit and basal cell carcinomas, and was considered to be a purely follicular keratin (27). CK17 is typically expressed in the suprabasal cells of the outer root sheath (ORS) of the hair follicle, the sebaceous duct, the suprabasal cells of the
Table IV. Summary of the statistical analysis of cytokeratin 17 central staining in keratoacanthoma cases.

Statistical analysis

No. of cases $(\%)$

Sensitivity

$22 / 24(92)^{\mathrm{a}}$

Specificity

$19 / 27(70)^{\mathrm{a}}$

PPV

$22 / 30(73)^{\mathrm{a}}$

NPV

$19 / 21(90)^{\mathrm{a}}$

${ }^{\mathrm{a}} \mathrm{P}<0.0001$ calculated using the Fisher's exact test. PPV, positive predictive value; NPV, negative predictive value.

sebaceous gland, the basal cells of sweat glands and a few epidermal basal cells at sites of entry of the acrosyringium (15). CK17 protein expression is induced in activated keratinocytes in the suprabasal layers of the epidermis, despite the fact that the normal epidermis does not positively stain for CK17 (15). CK17 expression has been reported in cultured wild-type epidermis and under hyperproliferative conditions, including 


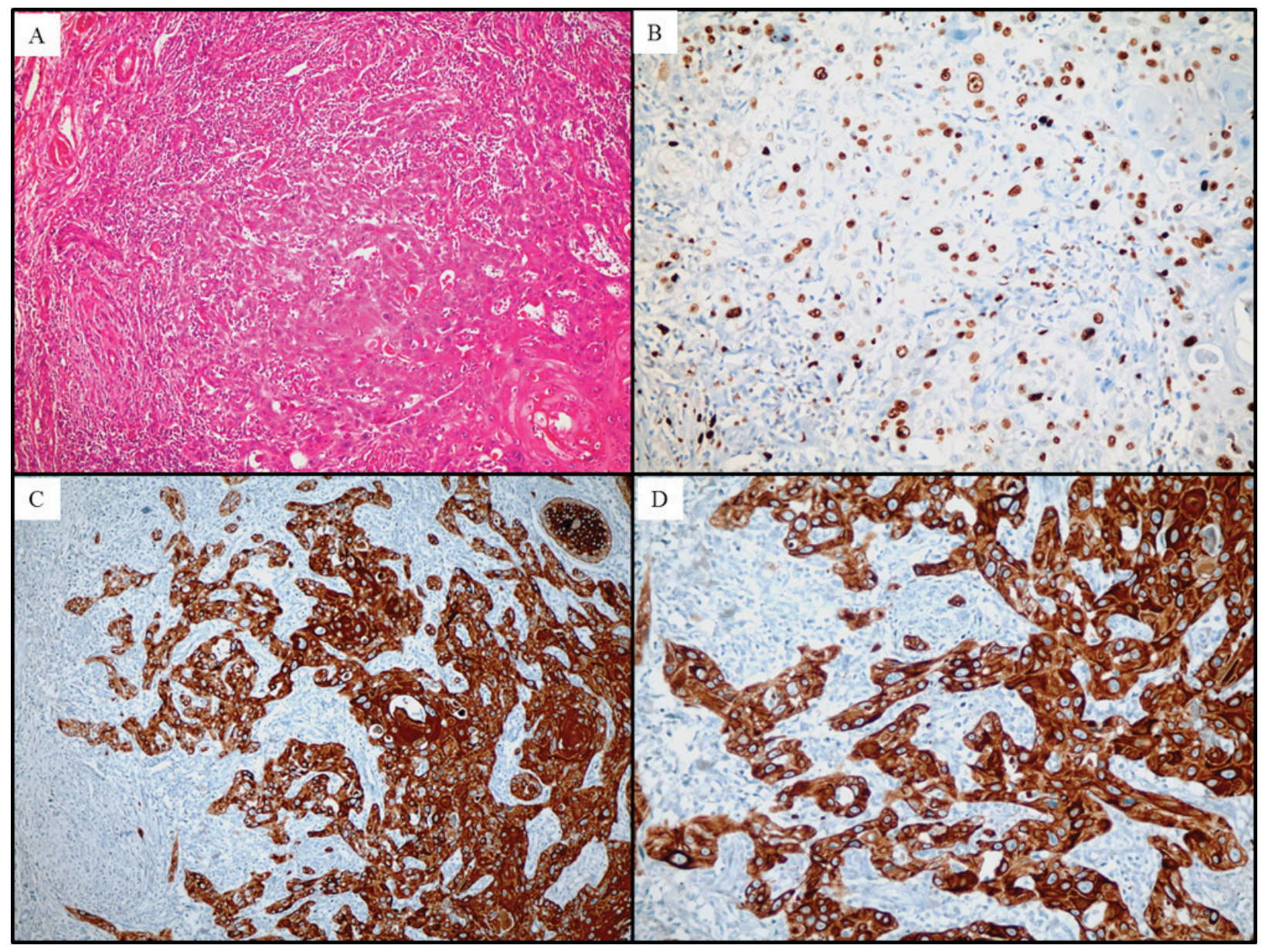

Figure 4. Representative images of (A) hematoxylin and eosin-stained SCC (magnification, 100) exhibiting (B) a proliferation marker protein Ki-67 IHC DP (magnification, x200), and a cytokeratin 17 IHC DP at (C) magnification x100 and (D) magnification x200. These staining patterns make up the SCC-like staining pattern. SCC, squamous cell carcinoma. DP, diffuse staining pattern; IHC, immunohistochemistry.

Table V.Proliferation marker protein Ki-67 staining patterns in the SCC and KA cases.

\begin{tabular}{lrr}
\hline & \multicolumn{3}{c}{$\begin{array}{c}\text { Cancer type } \\
\text { (no. of cases) }\end{array}$} \\
\cline { 2 - 3 } Staining pattern & SCC & KA \\
\hline Peripheral & 5 & 24 \\
Diffuse & 22 & 0
\end{tabular}

SCC, squamous cell carcinoma; KA, keratoacanthoma.

psoriasis, warts and wound healing, and is thought to reflect a hyperproliferative cell state $(9,15,28)$. CK17 is considered to be an early marker of keratinocyte activation following injury, and is expressed in migrating epithelial cells (29). In addition, CK17 staining has been observed in the basal cells of complex epithelial groups, including glandular epithelium containing a myoepithelial component, and transitional and pseudostratified epithelia (5). In a previous study, CK17 was reported to be a novel and interdependent regulator of hair cycling (30).

SCC CK17 expression has been reported in the skin, oral cavity, cervix, larynx, esophagus, anus and lung $(9-12,31)$.
Table VI. Summary of the statistical analysis of proliferation marker protein Ki-67 diffuse staining in squamous cell carcinoma cases.

\begin{tabular}{ll} 
Statistical analysis & No. of cases $(\%)$ \\
\hline Sensitivity & $22 / 27(81)^{\mathrm{a}}$ \\
Specificity & $24 / 24(100)^{\mathrm{a}}$ \\
PPV & $22 / 22(100)^{\mathrm{a}}$ \\
NPV & $24 / 27(89)^{\mathrm{a}}$
\end{tabular}

${ }^{\mathrm{a}} \mathrm{P}<0.0001$ calculated using the Fisher's exact test. PPV, positive predictive value; NPV, negative predictive value.

Divani and Kalodimos (12) observed that premalignant and malignant cells of the cervix exhibited CK17 expression, while wild-type ectocervical epithelial cells did not. Kitamura et al (11) demonstrated that CK17 expression was associated with differentiation and malignancy in oral SCC, indicating that it is a suitable biomarker of malignant transformation. Nazarian et al (10) reported that invasive anal squamous neoplastic lesions exhibited a CK17 PP or DP, in contrast to anal intraepithelial neoplasia. Proby et al (9) studied CK17 expression in skin SCC, and observed a CK17 


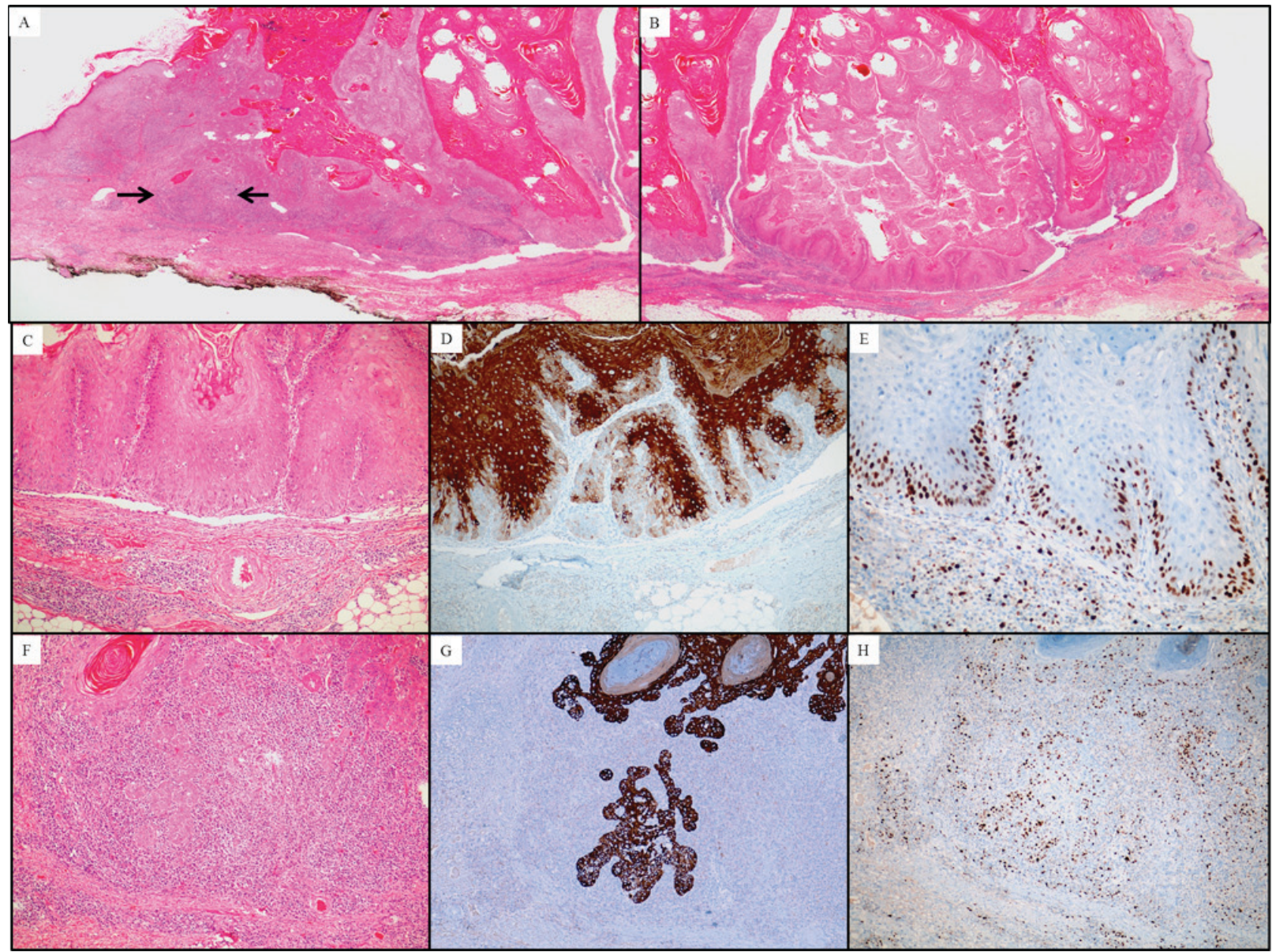

Figure 5. Representative images of H\&E-stained KA-like SCC at magnification, $\mathrm{x} 20$ in (A) one field of vision and (B) another field of vision, and (C) magnification x100, exhibiting a KA-like (D) CK17 (magnification, x100) or (E) Ki-67 (magnification, x200) IHC staining pattern. The invasive area exhibits (F) H\&E-stained cytological atypia (magnification, x100), and an SCC-like (G) CK17 (magnification, x100) or (H) Ki-67 (magnification, x100) IHC staining pattern. Black arrowhead, invasive area. KA, keratoacanthoma; SCC, squamous cell carcinoma; CK17, cytokeratin 17; Ki-67, proliferation marker protein Ki-67; H\&E, hematoxylin and eosin; IHC, immunohistochemistry.

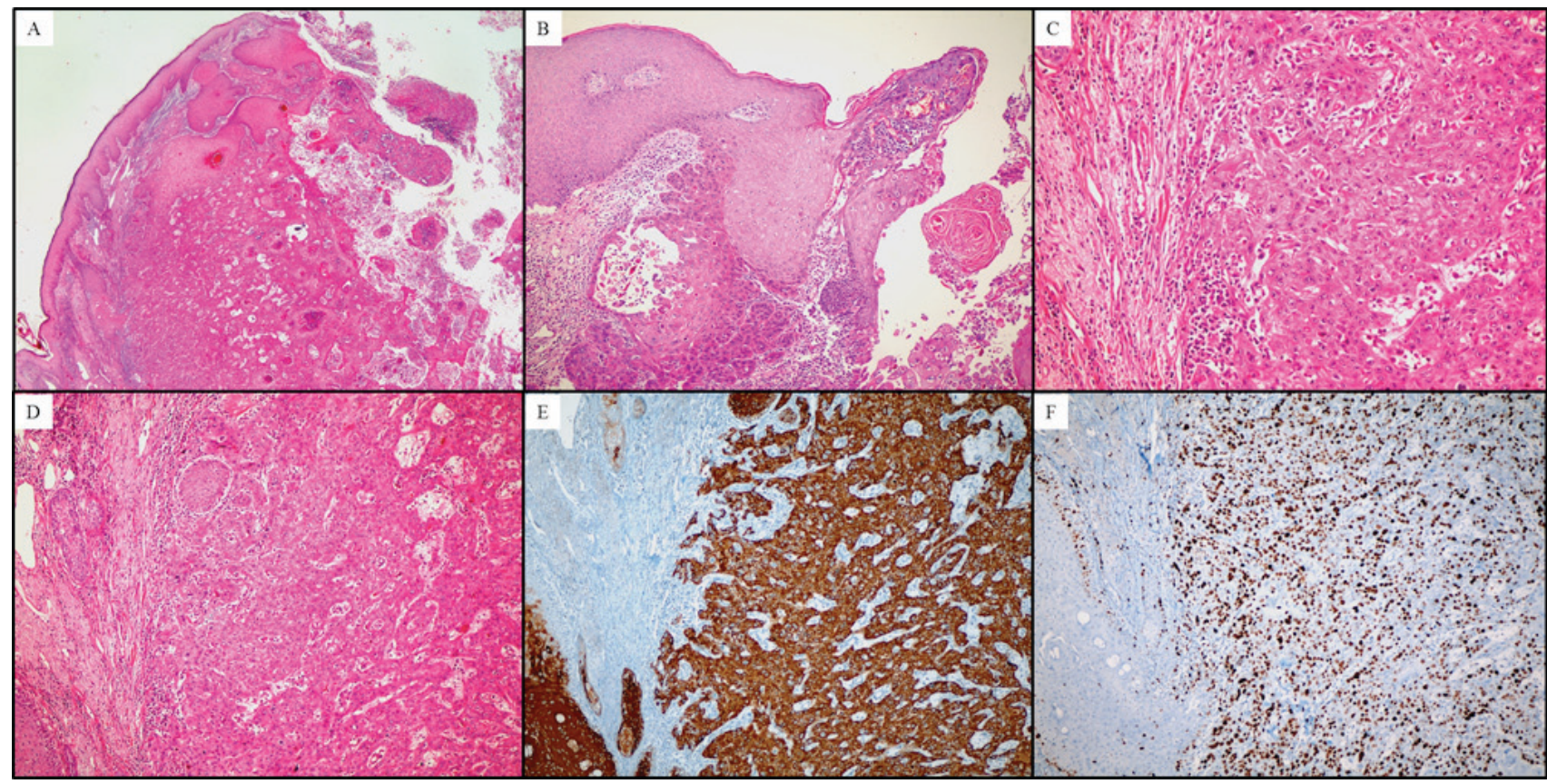

Figure 6. Representative images of crateriform SCC. Representative images of (A) the H\&E-stained crateriform architecture (magnification, $\mathrm{x} 40$ ), (B) H\&E-stained actinic keratosis adjacent to the lesion (magnification, x100), (C) H\&E-stained cytological atypia (magnification, x200), (D) an infiltrative H\&E staining pattern (magnification, x100), and an SCC-like (E) cytokeratin 17 (magnification, x100) or (F) proliferation marker protein Ki-67 (magnification, x100) immunohistochemical staining pattern. SCC, squamous cell carcinoma; H\&E, hematoxylin and eosin. 


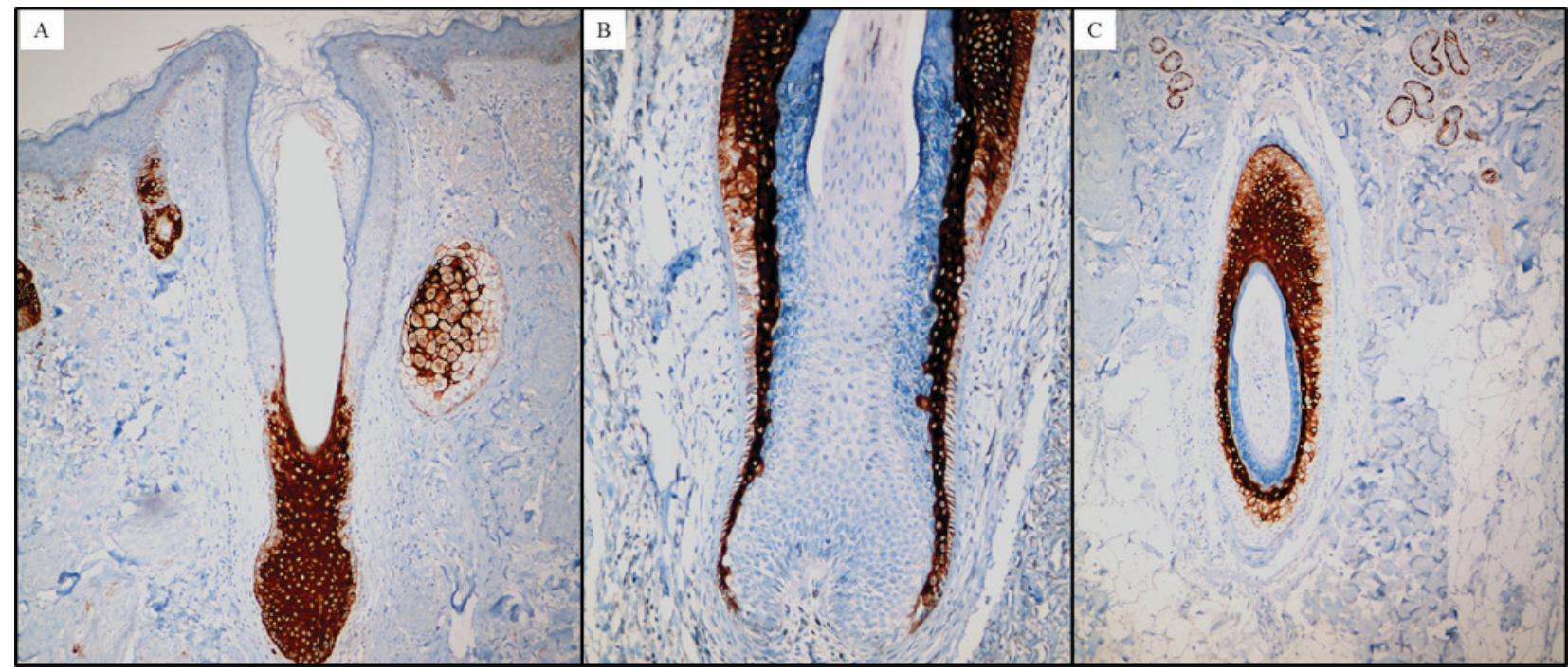

Figure 7. Representative images of the suprabasal cells of the ORS. (A) The normal hair follicle and sebaceous gland cells stain positively for CK17, while the epidermal cells do not (magnification, x100). The majority of ORS basal cells (B) stain weakly for CK17 (magnification, x200) or (C) do not stain at all (magnification, x100). Immunohistochemical staining used for all. ORS, outer root sheath.

DP in the basal and suprabasal cells of invasive SCC cases. To the best of our knowledge, no studies have been performed to evaluate the CK17 expression pattern in KA, although it is known that CK17 is expressed in hair-follicle-derived tumors, including KA.

In the present study, the utility of CK17 and Ki-67 expression in distinguishing between KA and SCC was investigated. All cases of KA exhibited a Ki-67 PP, whereas 22/27 (81\%) SCC cases exhibited a Ki-67 DP. The sensitivity and specificity of a Ki-67 DP in the identification of SCC was 81 and $100 \%$, respectively. Additionally, 22/24 (92\%) KA cases exhibited a CK17 CP, while 19/27 (70\%) SCC cases exhibited a CK17 DP. The sensitivity and specificity of a CK17 CP in the identification of KA was 92 and $70 \%$, respectively. Therefore, the results of the present study suggest that the presence of a Ki-67 DP or CK17 CP may be used as a biomarker of SCC and KA, respectively.

In the present study, it was observed that the basal cells in KA tumor lobules exhibited positive Ki-67 staining and negative/weak CK17 staining, whereas the suprabasal cells exhibited positive CK17 staining and negative Ki-67 staining. This staining pattern was named the KA-like staining pattern (Ki-67 PP and CK17 CP). A total of 22/24 (92\%) KA cases and 2/27 (7\%) SCC cases exhibited a KA-like staining pattern. The majority of SCC cases exhibited a Ki-67 and CK17 DP, and this was named the SCC-like staining pattern. A total of 16/27 (59\%) SCC cases exhibited a SCC-like staining pattern, while and no KA cases exhibited this pattern.

Lesion sections that appeared morphologically similar to KA in KA-like SCC cases exhibited a KA-like immunohistochemical staining pattern, whereas the majority of the lesions (morphologically similar to SCC) exhibited an SCC-like staining pattern. These results may be due to the difficulty in determining the characteristics of KA-like SCC and the association between KA, KA-like SCC and conventional SCC. The KA-like SCC cases exhibited rapid growth, similar to that of the KA cases, which is consistent with a previous study (2). There was potential subsequent regression in the KA-like SCC cases, similar to that of the KA cases. Accordingly, the histological features of KA-like SCC may be simply one histopathological type observed during the natural evolution of KA and one step in the process of KA evolution. However, KA-like SCCs may also be KAs, which exhibit early malignant transformation. In a previous study, a histopathological spectrum of epithelial neoplasms induced by sorafenib, which include typical KA, KA-like SCC and invasive SCC, has been suggested (32). This supports the hypothesis that KA-like SCC's are borderline lesions between KA and invasive SCC.

The results of the present study suggest that crateriform SCC is identical to conventional SCC from an immunological and clinical aspect, as all the crateriform SCC cases (4/4) exhibited an SCC-like staining pattern and were characterized as long-standing nodules.

Consistent with previous studies $(8,9,15,29,30)$, CK17 staining was absent in wild-type epidermal cells with the exception of focal staining adjacent to the lesions. CK17 was expressed in the suprabasal cells of the ORS of the wild-type hair follicle, which is consistent with previous studies. The CK17 CP detected in KA resembles the staining pattern of the ORS, which supports the theory that KA is a tumor of follicular origin derived from ORS cells (4).

In conclusion, a KA-like staining pattern was observed in the majority of KA cases examined in the present study, while it was rarely detected in SCC cases. By contrast, an SCC-like staining pattern was observed in the majority of SCC cases but in none of the KA cases. The CK17 CP exhibited high sensitivity and specificity for the detection of KA, while the Ki-67 DP exhibited high sensitivity and specificity for the detection of SCC. CK17 and Ki-67 may therefore be effective immunohistochemical markers for distinguishing between SCC and KA.

\section{Acknowledgements}

This abstract was presented at the XXXI International Congress of the International Academy of Pathology and 
the 28th Congress of the European Society of Pathology, September 28, 2016 in Cologne, Germany and was published as Abstract no. PS-15-025 in Virchows Archiv European Journal of Pathology volume 469.

\section{References}

1. Tan KB, Tan SH, Aw DC, Jaffar H, Lim TC, Lee SJ and Lee YS Simulators of squamous cell carcinoma of the skin: Diagnostic challenges on small biopsies and clinicopathological correlation. J Skin Cancer 2013: 752864, 2013.

2. Misago N, Inoue T, Koba S and Narisawa Y: Keratoacanthoma and other types of squamous cell carcinoma with crateriform architecture: Classification and identification. J Dermatol 40: 443-452, 2013.

3. Savage JA and Maize JC Sr: Keratoacanthoma clinical behavior: A systematic review. Am J Dermatopathol 36: 422-429, 2014.

4. Wagner VP, Martins MD, Dillenburg CS, Meurer L, Castilho RM and Squarize CH: Histogenesis of keratoacanthoma: Histochemical and immunohistochemical study. Oral Surg Oral Med Oral Pathol Oral Radiol 119: 310-317, 2015.

5. Lu S, Tiekso J, Hietanen S, Syrjänen K, Havu VK and Syrjänen S: Expression of cell-cycle proteins p53, p21 (WAF-1), PCNA and $\mathrm{Ki}-67$ in benign, premalignant and malignant skin lesions with implicated HPV involvement. Acta Derm Venereol 79: 268-273, 1999.

6. Scola N, Segert HM, Stücker M, Altmeyer P, Gambichler T and Kreuter A: Ki-67 may be useful in differentiating between keratoacanthoma and cutaneous squamous cell carcinoma. Clin Exp Dermatol 39: 216-218, 2014.

7. Connolly M, Narayan S, Oxley J and de Berker DA: Immunohistochemical staining for the differentiation of subungual keratoacanthoma from subungual squamous cell carcinoma. Clin Exp Dermatol 33: 625-628, 2008.

8. Troyanovsky SM, Guelstein VI, Tchipysheva TA, Krutovskikh VA and Bannikov GA: Patterns of expression of keratin 17 in human epithelia: Dependency on cell position. J Cell Sci 93: 419-426, 1989.

9. Proby CM, Churchill L, Purkis PE, Glover MT, Sexton CJ and Leigh IM: Keratin 17 expression as a marker for epithelial transformation in viral warts. Am J Pathol 143: 1667-1678, 1993.

10. Nazarian RM, Primiani A, Doyle LA, Linskey KR, Duncan LM, Odze RD and Zukerberg LR: Cytokeratin 17: An adjunctive marker of invasion in squamous neoplastic lesions of the anus. Am J Surg Pathol 38: 78-85, 2014.

11. Kitamura R, Toyoshima T, Tanaka H, Kawano S, Kiyosue T, Matsubara R, Goto Y, Hirano M, Oobu K and Nakamura S: Association of cytokeratin 17 expression with differentiation in oral squamous cell carcinoma. J Cancer Res Clin Oncol 138: 1299-1310, 2012.

12. Divani S and Kalodimos G: Expression of cytokeratins 8 and 17 as a diagnostic marker of cervical intraepithelial neoplasia. Arch Oncol 18: 88-90, 2010.

13. Sun TT, Eichner R, Nelson WG, Tseng SC, Weiss RA, Jarvinen M and Woodcock-Mitchell J: Keratin classes: Molecular markers for different types of epithelial differentiation. J Invest Dermatol 81 (1 Suppl): 109s-115s, 1983.

14. Purkis PE, Steel JB, Mackenzie IC, Nathrath WB, Leigh IM and Lane EB: Antibody markers of basal cells in complex epithelia. J Cell Sci 97: 39-50, 1990.

15. Yamamoto $\mathrm{O}$ and Asahi $\mathrm{M}$ : Cytokeratin expression in trichoblastic fibroma (small nodular type trichoblastoma), trichoepithelioma and basal cell carcinoma. Br J Dermatol 140: 8-161, 1999.
16. Rook A and Whimster I: Keratoacanthoma-a thirty year retrospect. Br J Dermatol 100: 41-47, 1979.

17. Godbolt AM, Sullivan JJ and Weedon D: Keratoacanthomas with perineural invasion: A report of 40 cases. Australas J Dermatol 42: 168-171, 2001.

18. Hodak E, Jones RE and Ackerman AB: Solitary keratoacanthoma is a squamous cell carcinoma: Three examples with metastases. Am J Dermatopathol 15: 332-342, 343-352, 1993.

19. Schwartz RA, Tarlow MM and Lambert WC: Keratoacanthomalike squamous cell carcinoma within the fibroepithelial polyp. Dermatol Surg 30: 349-350, 2004.

20. Cabrijan L, Lipozencić J, Batinac T, Lenković M and Zgombić ZS: Difference between keratoacanthoma and squamous cell carcinoma using TGF-alpha. Coll Antropol 37: 147-150, 2013.

21. Vasiljević N, Andersson K, Bjelkenkrantz K, Kjellström C, Månsson H, Nilsson E, Landberg G, Dillner J and Forslund O: The Bcl-xL inhibitor of apoptosis is preferentially expressed in cutaneous squamous cell carcinoma compared with that in keratoacanthoma. Int J Cancer 124: 2361-2366, 2009.

22. Papadavid E, Pignatelli M,Zakynthinos S, Krausz T and Chu AC: The potential role of abnormal E-cadherin and alpha-, beta- and gamma-catenin immunoreactivity in the determination of the biological behaviour of keratoacanthoma. Br J Dermatol 145: 582-589, 2001

23. Lammoglia-Ordiales L, Toussaint-Caire S, Contreras-Barrera M, Fonte-Avalos V, Rodriguez-Carreón AA, Rivera-Macias S and Dominguez-Cherit J: Assessment of syndecan-1 (CD138) and Ki-67 expression for differentiating keratoacanthoma and squamous cell carcinoma. J Drugs Dermatol 12: e53-e58, 2013.

24. Shimizu T, Muto M, Murakami T, Furumoto H, Mogami S and Asagami C: Overexpression of p53 protein associated with proliferative activity as evaluated by Ki-67 immunostaining in well-differentiated squamous cell carcinoma of the skin. Dermatology 195: 224-227, 1997.

25. Watanabe IC, Magalhães RF, de Moraes AM, Stelini RF, Cintra GF, Metze K and Cintra ML: Keratoacanthoma and Keratoacanthoma-Like Squamous Cell Carcinoma: Similar morphology but different pathogenesis. Medicine 94: e934, 2015.

26. Basta-Juzbasić A, Klenkar S, Jakić-Razumović J, Pasić A and Loncarić D: Cytokeratin 10 and Ki-67 nuclear marker expression in keratoacanthoma and squamous cell carcinoma. Acta Dermatovenerol Croat 12: 251-256, 2004.

27. Moll R, Franke WW, Volc-Platzer B and Krepler R: Different keratin polypeptides in epidermis and other epithelia of human skin: A specific cytokeratin of molecular weight 46,000 in epithelia of the pilosebaceous tract and basal cell carcinoma. J Cell Biol 95: 285-295, 1982

28. Wilson CL, Dean D, Lane EB, Dawber RP and Leigh IM: Keratinocyte differentiation in psoriatic scalp: Morphology and expression of epithelial keratins. Br J Dermatol 131: 191-200, 1994.

29. McGowan KM and Coulombe PA: Onset of keratin 17 expression coincides with the definition of major epithelial lineages during skin development. J Cell Biol 143: 469-486, 1998.

30. Tong $X$ and Coulombe PA: Keratin 17 modulates hair follicle cycling in a TNFalpha-dependent fashion. Genes Dev 20: 1353-1364, 2006

31. Lan YJ, Chen H, Chen JQ, Lei QH, Zheng M and Shao ZR: Immunolocalization of vimentin, keratin 17, Ki-67, involucrin, $\beta$-catenin and E-cadherin in cutaneous squamous cell carcinoma. Pathol Oncol Res 20: 263-266, 2014.

32. Arnault JP, Wechsler J, Escudier B, Spatz A, Tomasic G, Sibaud V, Aractingi S, Grange JD, Poirier-Colame V, Malka D, et al: Keratoacanthomas and squamous cell carcinomas in patients receiving sorafenib. J Clin Oncol 27: e59-e61, 2009. 